\title{
Influence of Grass Pollen Immunotherapy on Cellular Infiltration and Cytokine mRNA Expression during Allergen-induced Late-Phase Cutaneous Responses
}

\author{
V. A. Varney, Q. A. Hamid, M. Gaga, Sun Ying, M. Jacobson, A. J. Frew, A. B. Kay, and S. R. Durham \\ Department of Allergy and Clinical Immunology, National Heart \& Lung Institute, London, United Kingdom
}

\begin{abstract}
We have studied the influence of grass pollen immunotherapy on cellular infiltration and cytokine mRNA expression during allergen-induced late-phase cutaneous responses. In a doubleblind, placebo-controlled trial of immunotherapy in $\mathbf{4 0}$ adult hay fever sufferers, clinical improvement was accompanied by a decrease in the size of the late-phase skin response. When the immunotherapy-treated group was compared with the placebo group, analysis of skin biopsies obtained $24 \mathrm{~h}$ after intradermal allergen revealed a significant reduction in the number of infiltrating CD3+ $(P=0.04)$ and $\mathrm{CD4}+(P=0.009)$ cells and a trend for a decrease in EG2 + eosinophils $(P=0.08)$. Treatment did not influence allergen-induced recruitment of $\mathrm{CD8}+$ cells, neutrophils, or macrophages. Unexpected increases in expression of CD25 $(P=0.006)$ and HLA-DR $(P=0.007)$ were observed in the actively treated group. In situ hybridization using a panel of riboprobes demonstrated " $T_{H}$ 2-type" (IL4, IL-5) cytokine mRNA responses in both groups of patients. In contrast, significant hybridization for IL-2 (8/16 patients, $P$ $=0.02)$ and for interferon-gamma (6/16 patients, $P=0.04)$ was observed only in the actively treated group. These findings indicate that immunotherapy is associated with suppression of allergen-induced CD4+ T lymphocyte infiltration, but among the cells that are recruited, there is upregulation of CD25 and HLA-DR. At least in this model, immunotherapy does not appear to affect expression of $T_{\mathbf{H}}$ 2-pattern cytokines in response to allergen exposure, but expression of mRNA for Th1-type cytokines was enhanced in half of the patients. The results support the view that immunotherapy may possibly be working through induction of T cell tolerance. (J. Clin. Invest. 1993. 92:644-651.) Key words: immunotherapy • immediate hypersensitivity • t-lymphocytes • eosinophils • immunohistology • cytokines
\end{abstract}

\section{Introduction}

Immunotherapy has been used for over 80 years and has been shown to be an effective form of treatment for allergic rhinitis (1-3). The mechanism by which immunotherapy exerts its beneficial effect is unclear, but it has been widely suggested that immunotherapy may act by influencing production of allergen-specific IgE or IgG (4-7). We recently reported a double-

Address correspondence and reprint requests to Dr. S. R. Durham, Department of Allergy and Clinical Immunology, National Heart \& Lung Institute, Dovehouse Street, London, SW3 6LY, United Kingdom.

Received for publication 6 July 1992 and in revised form 3 February 1993.

J. Clin. Invest.

(c) The American Society for Clinical Investigation, Inc.

0021-9738/93/08/0644/08 $\$ 2.00$

Volume 92, August 1993, 644-651 blind placebo-controlled trial of allergen injection immunotherapy using a biologically standardized grass pollen extract (Phleum pratense, Alutard SQ; ALK, Horsholm, Denmark) in 40 adult patients with severe summer hay fever whose symptoms in previous pollen seasons were uncontrolled by antiallergic drugs (8). Immunotherapy was highly successful in reducing clinical symptoms and requirements for topical and oral rescue medications. Clinical improvement was accompanied by a decrease in the size of the late-phase cutaneous response after intradermal allergen challenge. It is possible that the efficacy of immunotherapy may be related to this ability to inhibit allergen-induced late-phase responses (9-12). We have previously reported that allergen-induced late-phase cutaneous responses are associated with infiltration by CD4+ T lymphocytes and with the recruitment and activation of eosinophils (13). Using in situ hybridization and a panel of riboprobes against cytokine mRNA, we further demonstrated increased expression of $\mathrm{T}_{\mathrm{H}}$ 2-type cytokines IL-3, IL-4, IL5, and GM-CSF (14). In this study we have examined the influence of grass pollen immunotherapy on cellular infiltration and cytokine mRNA expression during allergen-induced late-phase cutaneous responses. Our initial hypothesis was that immunotherapy might act by modulating CD4+ and/or CD8+ T lymphocyte infiltration with downregulation of transcription of $T_{H}$ 2-type cytokines.

\section{Methods}

40 patients were selected according to the following criteria: $(a)$ history of severe summer hay fever, $(b)$ poor symptom control in previous years despite regular antiallergic treatment that included antihistamines and intranasal corticosteroids and sodium cromoglycate, and $(c)$ positive skin prick test (weal diameter $>5 \mathrm{~mm}$ ) to Timothy grass pollen extract (Phleum pratense; ALK, Horsholm, Denmark) (8). Patients were excluded if they had received injection immunotherapy in the previous $5 \mathrm{yr}$, if they gave any history of asthma or eczema, or if they had any other significant medical or immunological disease.

Study design. The study was approved by the Royal Brompton National Heart and Lung Hospital Ethics Committee and was performed with the patients' written informed consent (8). Patients were stratified according to disease severity then randomized to receive twice-weekly injections of Alutard SQ (Phleum pratense) or matched placebo injections $(0.9 \%$ sodium chloride, intermittently spiked with $0.01 \mathrm{mg} / \mathrm{ml}$ histamine, in order to provoke local erythema and itching). The two groups were well matched for disease severity (Table I). Active or placebo injections were administered twice weekly up to a maintenance volume of $1 \mathrm{ml}$ (representing 100,000 SQ units $(32,000$ biological units $[\mathrm{BU}]^{1}$ ) Phleum pratense in the actively treated group). The maintenance volume was achieved in all patients within 6-10 wk. Two systemic reactions were observed: one episode of mild urticaria at $2 \mathrm{~h}$ after injection and one at $10 \mathrm{~min}$ (flushing and chest tightness), which responded promptly to subcutaneous adrenaline. Thereafter, injections were administered monthly for 9 mo. During the pollen sea-

1. Abbreviation used in this paper: $\mathrm{BU}$, biological units. 
son, rescue medication was provided in the form of sodium cromoglycate eyedrops and nasal spray (Opticrom and Rynacrom; Fisons Pharmaceuticals, Loughborough, UK) and a short-acting antihistamine ( 8 mg acrivastine; Semprex, The Wellcome Foundation Ltd., London, UK). If symptoms remained uncontrolled despite this medication, a $7-\mathrm{d}$ reducing course of prednisolone was given ( $30 \mathrm{mg}$ daily for $2 \mathrm{~d}$ then reducing by $5 \mathrm{mg}$ each day to zero). Daily symptom scores and medication requirements were recorded on diary cards from April through September 1989.

Allergen extracts. Immunotherapy was performed using a single batch of aluminium-adsorbed depot grass pollen extract Phleum pratense (Alutard SQ; ALK). Skin prick testing was performed with Timothy grass pollen extract in albumin diluent $(50 / 50$ glycerol/albumin $0.03 \mathrm{mg} / \mathrm{ml}$ [Soluprick SQ, Phleum pratense; $A L K$ ] Intradermal skin provocation tests were performed using Aquagen SQ (an aqueous extract of Phleum pratense in $0.03 \%$ human serum albumin diluent with $0.5 \%$ phenol) and with $0.9 \%$ sodium chloride.

Skin provocation tests. Skin sensitivity to allergen was measured in all subjects before and after 9 mo treatment (i.e., March and December 1989). Intradermal challenges were performed at the same time of day in duplicate, $10 \mathrm{~cm}$ apart, with $30 \mathrm{BU}(0.02 \mathrm{ml})$ of intradermal Phleum pratense and allergen diluent $(0.02 \mathrm{ml})$. The size of the immediate ( 15 $\mathrm{min}$ ) and late-phase ( $24 \mathrm{~h}$ ) reaction was recorded as the mean of the longest and the perpendicular diameters. These challenges were performed on the extensor aspect of the forearm in order to reduce the visibility of the scar from subsequent biopsies.

Skin biopsies. Skin biopsies were obtained after 9 mo treatment using a 3-mm disposable punch (15). In order to minimize the possible influence of the preceding immunotherapy injection on the occurrence or magnitude of skin responses to intradermal allergen, all skin biopsies were taken exactly $1 \mathrm{mo}$ after the previous injection. After obtaining local anesthesia with $1 \%$ lignocaine, four biopsies were taken from the center of duplicate allergen and diluent control sites. Biopsies for immunohistology were immediately placed in PBS and snap-frozen in ornithine carbamyl transferase embedding medium using isopentane, precooled in liquid nitrogen. Biopsies were then stored at $-80^{\circ} \mathrm{C} .6-\mu \mathrm{m}$ sections were cut on a cryostat (Bright Instruments, Huntingdon, UK) and consecutive sections were placed on microscope slides. They were air dried for $1 \mathrm{~h}$, fixed in 50/50 acetone/methanol for $5 \mathrm{~min}$, and further air dried for $1 \mathrm{~h}$. The slides were then wrapped in pairs in aluminium foil and stored at $-20^{\circ} \mathrm{C}$ before immunostaining (13).

Biopsies for in situ hybridization were immediately placed in $4 \%$ paraformaldehyde in $0.1 \mathrm{M}$ PBS for $1 \mathrm{~h}$, followed by $15 \%$ sucrose/PBS for $1 \mathrm{~h}$, and then subsequently in $15 \%$ sucrose/PBS overnight. Biopsies were then placed in OCT embedding medium, snap frozen in isopentane precooled in liquid nitrogen, and stored at $-80^{\circ} \mathrm{C} .10-\mu \mathrm{m}$ cryostat sections were cut, and single sections were placed on poly-L-lysine coated microscope slides and then baked overnight at $37^{\circ} \mathrm{C}$. Slides were then stored at $-80^{\circ} \mathrm{C}$ in the presence of silica gel (14).

Immunohistology. Slides were allowed to defrost in their foil covering. Monoclonal antibody staining was detected by the alkaline phosphatase antialkaline phosphatase method (13). $20 \%$ normal human serum was used to prevent nonspecific binding of the second and third layer antibodies. Sections of human tonsil obtained at routine tonsillectomy operations were included as positive controls in each staining run. A mouse IgG2a myeloma protein was used as a negative control The monoclonal antibodies used were: CD45, CD3, CD4, CD25 (Becton Dickinson, Cowley, Oxford, UK); EG2, a monoclonal antibody that recognizes the cleaved, actively secreted form of eosinophil cationic protein ECP (Bradshaw Biologicals, Loughborough, Leicestershire, UK); CD8 and CD68 (macrophage) (DAKOPATTS, High Wycombe, UK). Polyclonal sheep antielastase (neutrophil), rabbit antimouse immunoglobulin, and APAAP reagents (DAKOPATTS). Optimal concentrations for immunostaining for each antibody were identified, such that discrete staining of individual cells was achieved with a low background. All other chemicals and solvents for immunohistology were purchased from BDH, Dagenham, Essex, UK).
For each monoclonal antibody, staining of all sections was completed in one experiment using the same batch of antibody.

In situ hybridization. All reagents were from Sigma Chemicals (Poole, Dorset, U.K.) unless otherwise indicated. Riboprobes labeled with ${ }^{35} \mathrm{~S}$ were prepared from cDNAs for IL-2, IL-3, IL-4, IL-5, GMCSF, and IFN-gamma (Glaxo Biogen, Geneva, Switzerland) as previously described (14). Permeabilization, prehybridization, and hybridization were performed as previously described (14). Incubation in $n$-ethylmaleimide iodoacetamide, and triethanolamine reduced nonspecific binding of the ${ }^{35} \mathrm{~S}$ probes. Negative controls employed were the sense probe (identical nucleotide sequence to mRNA) and pretreatment of slides with ribonuclease A (Promega, Southampton, UK). Positive controls were PHA-stimulated peripheral blood mononuclear cells (for IL-2 and IFN-gamma), and a T cell clone known to produce IL-3, IL-4, IL-5, and GM-CSF. Cells expressing cytokine mRNA were detected by discrete, dense deposits of silver grains on autoradiographs.

Quantitation. Slides were encoded and counted blind using a BH2 microscope (Olympus Corp., Lake Success, NY) at a magnification of 100 with an eyepiece graticule. For immunohistology, at least four sections from each biopsy were stained with each monoclonal antibody and a total of 2-3 grids per section were counted. The upper edge of the grid was placed at the epidermal junction. In areas containing sweat ducts and hair shafts, only intervening dermal regions were counted. The results were expressed as mean positive cells per field. The within observer coefficient of variation for repeat measurements was less than $5 \%$. Cells expressing positive hybridization signals for cytokine mRNA were counted in a similar fashion. The within observer coefficient of variation for repeat measurements was again less than $5 \%$.

Analysis. Data was analyzed using a statistical package (Minitab software; Minitab Inc., University Park, PA). Within individual subjects, cell counts after allergen were compared with the corresponding counts after diluent using the Wilcoxon matched-pairs signed ranks test. Between group comparisons of baseline cell counts (after diluent) and changes in cell counts after allergen (allergen minus diluent) were performed by the Mann Whitney U Test. $P$ values less than 0.05 were regarded as significant.

Single and multiple linear regression analyses were performed using the SAS statistical package (SAS Institute, Carey, NC) to search for correlations between the various cellular parameters, and either the diameter of late-phase skin responses or the difference between latephase response size before and after treatment. Associations were also sought among total seasonal symptom scores, the various cellular parameters, and the diameter of late-phase responses.

\section{Results}

The two patient groups were well matched for age, disease severity, and disease duration (Table I). There was a slight excess of males in the actively treated group, although this was not statistically significant.

Clinical efficacy. 37 of the 40 patients (93\%) completed the study. The three "dropouts" were in the placebo group. Completed diary cards were therefore available from 16 of the 19 placebo-treated patients and from 20 of the 21 who received Alutard SQ (8) (One set of diary cards was lost in the mail.). Clinical results have been reported previously (8) and are summarized in Table I. When the Alutard SQ-treated group was compared with the placebo group, there were significant reductions in seasonal symptoms $(P=0.001)$, in rescue medication use $(P=0.002)$, and in peak seasonal visual analogue scores $(P$ $=0.02$ ).

Effect of immunotherapyon skin tests. The size of the immediate and late skin responses after intradermal injection of 30 BU grass pollen extract (Phleum pratense) were recorded be- 


\begin{tabular}{|c|c|c|c|}
\hline & \multicolumn{2}{|c|}{ Treatment } & \\
\hline & Placebo & Alutard SQ & \\
\hline No. of patients & 19 & 21 & \\
\hline Male:female ratio & $8: 11$ & $14: 7$ & \\
\hline Mean (range) age (yr) & $37 \quad(23-52)$ & $34 \quad(19-51)$ & \\
\hline Mean (range) duration (yr) of allergy & $13.5(4-30)$ & $15.0(2-30)$ & \\
\hline \multicolumn{4}{|c|}{ Hay fever severity score* (no. of patients): } \\
\hline A & 9 & 9 & \\
\hline \multirow[t]{2}{*}{ B } & 10 & 12 & \\
\hline & $(n=16)$ & $(n=19)$ & \\
\hline \multicolumn{4}{|l|}{ Symptoms during pollen season } \\
\hline Total symptoms & 928 & 360 & $P<0.001$ \\
\hline Rescue medication & 627 & 129 & $P=0.002$ \\
\hline \multicolumn{4}{|l|}{ Peak season visual analogue } \\
\hline scores (scale $0-10$ ) & 5.5 & 2.2 & $P=0.02$ \\
\hline
\end{tabular}

* Severity score A, patients with skin prick test $>16 \mathrm{~mm}$; positive conjunctival provocation test at $\leq 300$ biological units/ml; history of symptoms for $\geq 10 \mathrm{wk}$ during season and previous oral and/or injected corticosteroids or both. Severity score B, patients with moderate to severe hay fever who did not fulfill all of above criteria.

fore and after 9 mo treatment (Fig. 1). The placebo- and Alutard SQ-treated patients were well matched for the size of both the immediate ( $15 \mathrm{~min}$ ) and late-phase $(24 \mathrm{~h})$ cutaneous response before immunotherapy. There was no significant relationship between the size of immediate and late-phase responses $(r=0.0001)$. The actively treated group showed a statistically significant decrease in the size of the immediate response (mean reduction $40 \%, P<0.02$ ) and the late-phase response (mean reduction $64 \%, P<0.001$ ) compared with the placebo-treated group. Gender had no influence on the size of immediate or late skin responses or the patients' responses to immunotherapy.

Immunohistology of cutaneous late-phase responses. After 9 mo treatment, the immunohistology of the cutaneous late- phase response was examined in 20 of the 21 patients who had received Alutard SQ, and in 16 of the 19 subjects who completed the course of placebo injections ( 3 placebo patients dropped out and one subject who received Alutard SQ completed the course of injections but declined to undergo repeat skin biopsies). Cell counts in the dermis $24 \mathrm{~h}$ after local provocation with grass pollen solution or with allergen diluent are presented in Table II.

Diluent control sites. When cell counts at diluent control sites were compared, the numbers of leukocytes (CD45+), T lymphocytes $(\mathrm{CD} 3+), \mathrm{CD} 4+$ cells, and macrophages $(\mathrm{CD} 68+)$ were virtually identical in the two treatment groups. Similarly there were no significant differences for the activation markers CD25 and HLA-DR. Only occasional neutro-

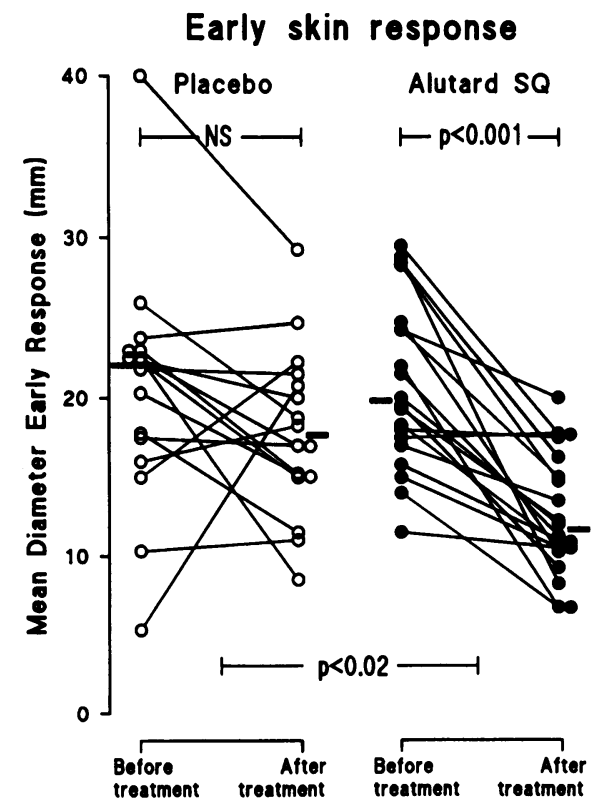

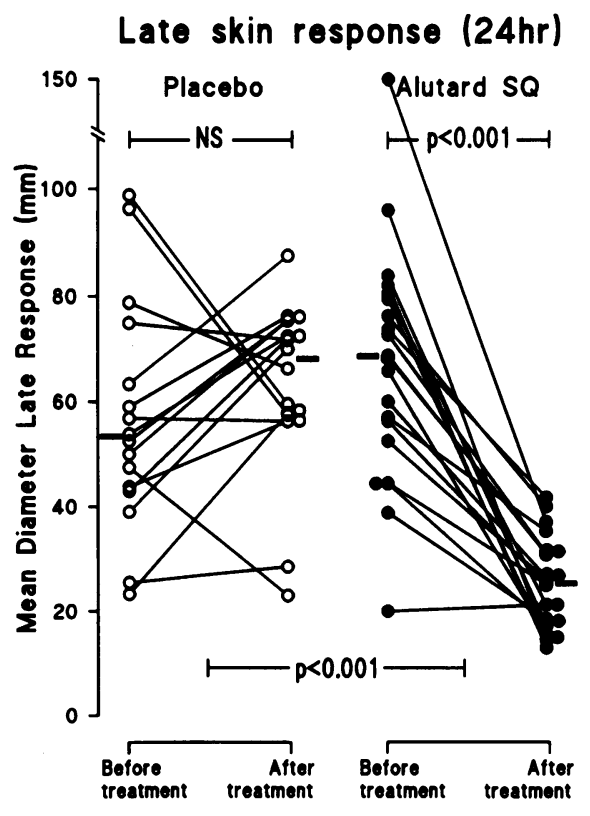

Figure 1 . The diameter of early ( 15 $\mathrm{min})$ and late ( $24 \mathrm{~h})$ skin responses after intradermal $30 \mathrm{BU}$ grass pollen extract before and after 9 mo treatment in placebo- (open circles) and Alutard SQ-(closed circles) treated patients. Median values are represented by the solid bars. NS, not significant. 
Table II. Immunohistology of the Cutaneous Late Phase Response after 9 mo Treatment with Placebo or Alutard SQ

\begin{tabular}{|c|c|c|c|c|c|c|c|c|}
\hline \multirow[b]{2}{*}{$\begin{array}{l}\text { Monoclonal } \\
\text { antibody }\end{array}$} & \multicolumn{3}{|c|}{ Placebo $(n=16)$} & \multicolumn{3}{|c|}{ Alutard SQ $(n=20)$} & \multicolumn{2}{|c|}{ Alutard SQ vs. Placebo } \\
\hline & $\begin{array}{c}\text { Control } \\
\text { (median) }\end{array}$ & $\begin{array}{c}\text { Grass } \\
\text { pollen } \\
\text { (median) }\end{array}$ & $\begin{array}{c}\text { Median } \\
\text { difference } \\
(95 \% \mathrm{CI})\end{array}$ & $\begin{array}{c}\text { Control } \\
\text { (median) }\end{array}$ & $\begin{array}{c}\text { Grass } \\
\text { pollen } \\
\text { (median) }\end{array}$ & $\begin{array}{c}\text { Median } \\
\text { difference } \\
(95 \% \mathrm{CI})\end{array}$ & $\begin{array}{c}\text { Median } \\
\text { difference } \\
(95 \% \mathrm{CI})\end{array}$ & $P$ value \\
\hline CD45 & 42 & 63 & $19(6,39)^{\ddagger}$ & 40 & 52 & $13(-5,23)^{*}$ & $-8(+9,-26)$ & 0.19 \\
\hline CD3 & 18 & 41 & $20(6.31)^{\S}$ & 19 & 30 & $11(-3,23)^{*}$ & $-12(+4,-28)$ & 0.04 \\
\hline CD4 & 27 & 57 & $24(10,41)^{\ddagger}$ & 27 & 37 & $3(-2,19)$ ns & $-19(-2,-37)$ & 0.009 \\
\hline CD8 & 2 & 7 & $5(-1,14)^{*}$ & 6 & 9 & $4(2,12)^{\ddagger}$ & $+1(+7,-9)$ & 0.89 \\
\hline EG2 & 0 & 33 & $32(20,49)^{\S}$ & 0 & 9 & $5(0,41)^{\ddagger}$ & $-18(-5,-32)$ & 0.08 \\
\hline \multicolumn{9}{|l|}{ Elastase } \\
\hline (neutrophils) & 1 & 22 & $20(12,28)^{\S}$ & 1 & 15 & $13(2,23)^{\S}$ & $-5(+4,-18)$ & 0.31 \\
\hline \multicolumn{9}{|l|}{ CD68 } \\
\hline (macrophages) & 19 & 31 & $10(-2,33)^{*}$ & 19 & 32 & $9(3,22)^{\ddagger}$ & $+2(+18,-20)$ & 0.85 \\
\hline $\mathrm{CD} 25$ & 4 & 5 & $1(-2,4)^{\mathrm{NS}}$ & 4 & 10 & $7(4,15)^{8}$ & $+7(+13,+2)$ & 0.006 \\
\hline HLA-DR & 46 & 59 & $19(-15,31)^{\mathrm{NS}}$ & 39 & 83 & $47(20,61)^{8}$ & $+27(+50,+4)$ & 0.007 \\
\hline
\end{tabular}

Median cell counts are shown for each monoclonal antibody together with median differences and $95 \%$ confidence intervals. Within groups, cell counts at grass pollen sites are compared with counts at control sites using the Wilcoxon test. Between groups, the net increases in cell counts (grass pollen minus control) are compared using the Mann Whitney $U$ test.

${ }^{*} P<0.05 ;{ }^{\ddagger} P<0.01 ;{ }^{\S} P<0.001 ; \mathrm{CI}$, confidence interval.

phils were observed, and eosinophils were absent. There was, however, a small but significant increase in the median number of CD8 + cells in the Alutard SQ-treated group compared with the placebo group $(6,95 \%$ CI $3-7$.V. $2,95 \%$ CI $0-5 ; P=0.04)$. The numbers of cells at these diluent-challenged sites were comparable with our previous studies using the same methods (13, $15,16)$ and studies of normal skin (17).

Within subject comparisons (allergen versus control sites). Next, cell counts $24 \mathrm{~h}$ after intradermal allergen were compared with control (diluent) sites. In the placebo-treated group, intradermal allergen caused significant increases in total leukocytes, $\mathrm{T}$ lymphocytes (CD3+), CD4+, and CD8+ T cell subsets and macrophages (CD68+). Highly significant increases were observed for eosinophils (EG2+) and for neutrophils (elastase+). Small, statistically nonsignificant increases in positive immunostaining for the activation markers CD25 and HLA-DR were also observed ( Table II). These results are again consistent with our previous observations using this model (13, $15,16)$. In the Alutard SQ-treated group, intradermal allergen induced significant increases in most cell counts compared with diluent control sites. In contrast to the placebo-treated group, intradermal allergen did not induce a significant increase in CD4+ cells, but there were highly significant increases in immunostaining for the activation markers CD25 and HLADR (Table II).

Between group comparisons. The magnitude of the net increases in cell counts (grass pollen minus control) were compared between the placebo and Alutard SQ-treated groups. Active treatment was associated with significant reduction in the recruitment of CD3+ cells $(P=0.04)$ and CD4+ cells $(P$ $=0.009$ ) after allergen challenge (Fig. 2 Table II). There was a trend for a reduction in the number of infiltrating eosinophils (median net counts 5 and 32 for Alutard SQ-treated group and placebo group respectively; $P=0.08$ ). The allergen-induced increases in expression of CD25 and HLA-DR in the Alutard SQ-treated group was highly significant when compared with the corresponding values for the control group $(P=0.006$ and
$P=0.007$ respectively; Fig. 3 , Table II). There were no significant differences between the two groups in the cellular response to allergen with regard to total leukocytes, CD8+ cells, neutrophils, or macrophages. Absolute cell counts at allergen-challenged sites were also compared between placebo- and Alutard SQ-treated patients. The differences were virtually identical to those observed when net increases in cell counts were used (data not shown).

Correlation analysis. In simple linear regression analysis, the size of the LPR at $24 \mathrm{~h}$ was found to be positively correlated to the numbers of CD4+ cells at allergen-challenged sites in the placebo-treated group $\left(r^{2}=0.352, P=0.015\right)$. This relationship was not present in the active group, reflecting the reduced CD4+ signal and smaller sized cutaneous responses. Multiple regression analysis did not reveal any additional associations.

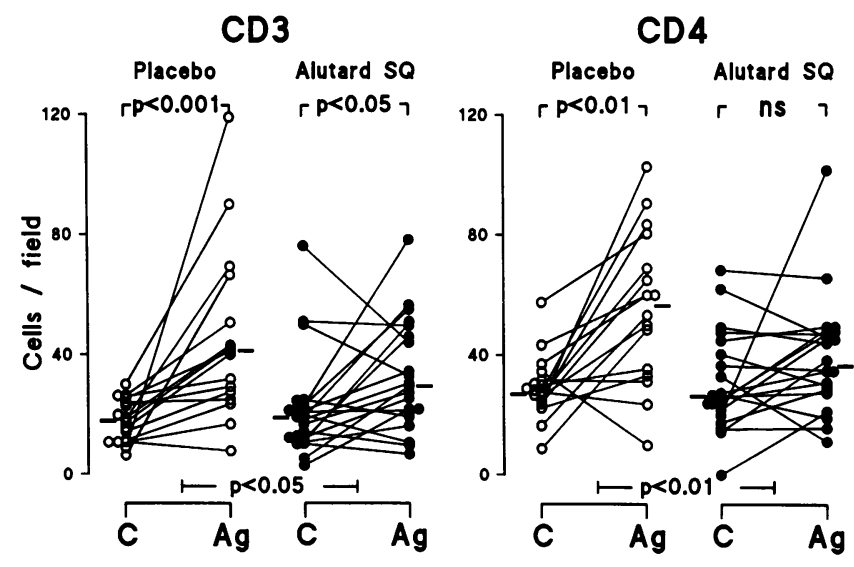

Figure 2. CD3+ and CD4+ cell counts in the dermis in placebo-(open circles) and Alutard SQ-(closed circles) treated groups after 9 mo treatment. Results are expressed as cells per field ( $100 \times$ magnification) $24 \mathrm{~h}$ after intradermal $30 \mathrm{BU}$ grass pollen extract $(\mathrm{Ag})$ compared with counts after control allergen diluent solution $(C)$. Median values are represented by the solid bars. NS, not significant. 

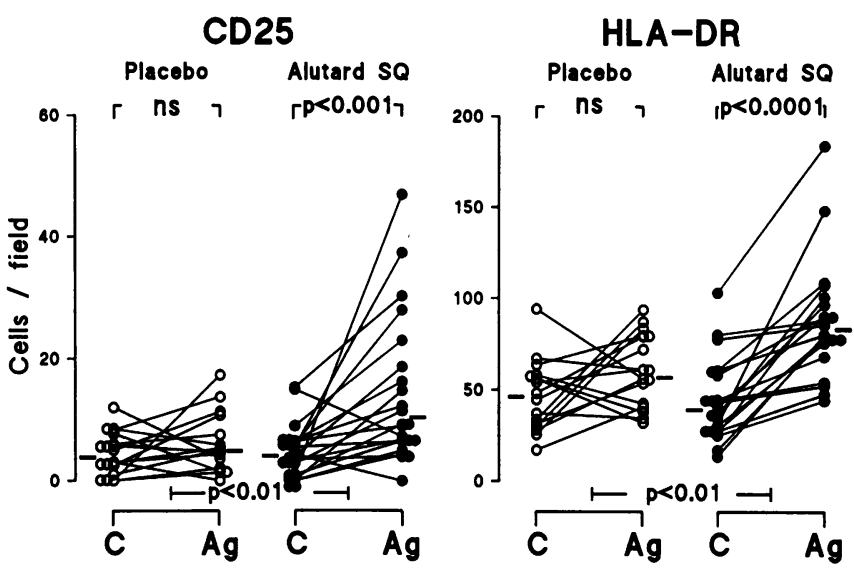

Figure 3. CD25+ and HLA-DR+ cell counts in placebo (open circles) and Alutard SQ (closed circles) groups after 9 mo treatment. Results are expressed as cells per field $(\times 100) 24 \mathrm{~h}$ after intradermal $30 \mathrm{BU}$ grass pollen extract $(\mathrm{Ag})$ compared with counts after the control allergen diluent solution (C). Median values are represented by the solid bars. NS, not significant.

With regard to the change in the size of the late response, the reduction in size was greater in the actively treated group, making it easier to find correlations in this group. The only cellular parameter that showed a correlation with the magnitude of the reduction in 24-h LPR size was the number of EG2 + cells: greater numbers of activated eosinophils at allergen-challenged sites were associated with a smaller reduction in LPR size $\left(r^{2}=0.361, P=0.005\right)$.

No significant associations were found among total seasonal symptom scores for either placebo or Alutard SQ-treated patients, the size of allergen-induced early or late responses, and cell counts in the dermis at $24 \mathrm{~h}$ after allergen challenge.

In situ hybridization of cutaneous late-phase responses. Biopsy material suitable for in situ hybridization was available from 16 of the actively treated group and from 15 of the placebo-treated group. The remaining 5 patients for whom biopsy material for immunohistology was available declined additional skin biopsies required for in situ hybridization studies. Median numbers of cells in the dermis expressing positive hybridization signals for each cytokine are shown in Table III. Only occasional positive hybridization signals were observed at control (diluent) sites in either treatment group. When com- pared with diluent sites, there were significant increases in IL-3, IL-4, IL-5, and GM-CSF expression at allergen sites in both the placebo and Alutard SQ-treated groups. Median cell counts at allergen sites and median differences (allergen minus diluent counts) for these $T_{H} 2$-type cytokines were lower in the Alutard SQ-treated group, but none of these differences was statistically significant when compared with the placebo group. A significant increase in positive hybridization signals for IL-2 was observed at allergen sites in half of the Alutard SQ-treated group $(P=0.02)$ but not in the placebo group (Fig. 4). Similarly, intradermal allergen induced a significant increase in positive hybridization signals for IFN-gamma $(P=0.04)$ in the Alutard SQ-treated group (6/16 patients) while IFN-gamma mRNA could not be detected in biopsies from the control or allergen sites from any of the placebo-treated patients. The subjects who showed increases in IFN-gamma were not necessarily those who demonstrated increases in IL-2. There were no significant associations among the size of either early or late-phase cutaneous responses total seasonal symptom scores during the pollen season and numbers of mRNA positive cells for either group. In the actively treated group there was a significant positive correlation between IL- 2 mRNA positive cells and IL-2R (CD25) expression $(r=0.66, P<0.05)$.

\section{Discussion}

We have confirmed our previous findings that human allergeninduced late cutaneous responses are accompanied by recruitment of CD4+ T lymphocytes and activated eosinophils (13, $15,16)$ and an increase in cytokine mRNA expression for $T_{H} 2$ type cytokines (14).

Our initial hypothesis was that after immunotherapy there would be a global reduction in T cell numbers, in markers of lymphocyte activation, and in eosinophils at allergen-challenged sites. In fact we observed the changes we expected in CD3+ and CD4+ cell numbers but found an unexpected increase in CD25 and HLA-DR expression. In proceeding to examine the in situ hybridization data, we revised our hypothesis that, because of the known effects of IL-2 and IFN-gamma on CD25 and HLA-DR expression, the observed reduction in CD4+ cell numbers might be accompanied by activation of cells with a TH1 pattern of cytokine expression. Our in situ hybridization studies confirmed ongoing $\mathrm{T}$ cell activation, with an increase in IL-2 mRNA in half of the actively treated pa-

Table III. In Situ Hybridization of Cutaneous Late Phase Responses after 9 mo Treatment with Placebo or Alutard SQ

\begin{tabular}{|c|c|c|c|c|c|c|c|c|c|c|}
\hline & \multicolumn{5}{|c|}{ Placebo $(n=15)$} & \multicolumn{5}{|c|}{ Alutard SQ $(n=16)$} \\
\hline & $\begin{array}{c}\text { Control } \\
\text { (median) }\end{array}$ & $\begin{array}{c}\text { Grass } \\
\text { pollen } \\
\text { (median) }\end{array}$ & $\begin{array}{c}\text { Median } \\
\text { difference }\end{array}$ & $\begin{array}{c}95 \% \\
\text { confidence } \\
\text { intervals }\end{array}$ & $P$ value & $\begin{array}{c}\text { Control } \\
\text { (median) }\end{array}$ & $\begin{array}{c}\text { Grass } \\
\text { pollen } \\
\text { (median) }\end{array}$ & $\begin{array}{c}\text { Median } \\
\text { difference }\end{array}$ & $\begin{array}{c}95 \% \\
\text { confidence } \\
\text { intervals }\end{array}$ & $P$ value \\
\hline IL-3 & 0 & 2.5 & 2.5 & $(0,4.4)$ & 0.01 & 0 & 2.5 & 1.4 & $(0.4,5.6)$ & 0.006 \\
\hline IL-4 & 0 & 4.0 & 4.0 & $(0,6.8)$ & 0.006 & 0 & 3.7 & 3.3 & $(1.8,5.0)$ & 0.003 \\
\hline IL-5 & 0 & 7.3 & 7.3 & $(2.7,8.4)$ & 0.003 & 0 & 3.3 & 3.2 & $(0,10.9)$ & 0.004 \\
\hline GM-CSF & 0 & 7.5 & 5.8 & $(4,10.6)$ & 0.002 & 0 & 6.8 & 3.7 & $(1.8,8.8)$ & 0.002 \\
\hline IL-2 & 0 & 0 & 0 & $(0,2.2)$ & NS & 0 & 1.7 & 0.4 & $(0,5.3)$ & 0.02 \\
\hline IFN-gamma & 0 & 0 & 0 & $(0,0)$ & NS & 0 & 0 & 0 & $(0,6.8)$ & 0.04 \\
\hline
\end{tabular}

Within groups, cell counts at grass pollen sites are compared with counts at control sites using the Wilcoxon test. 

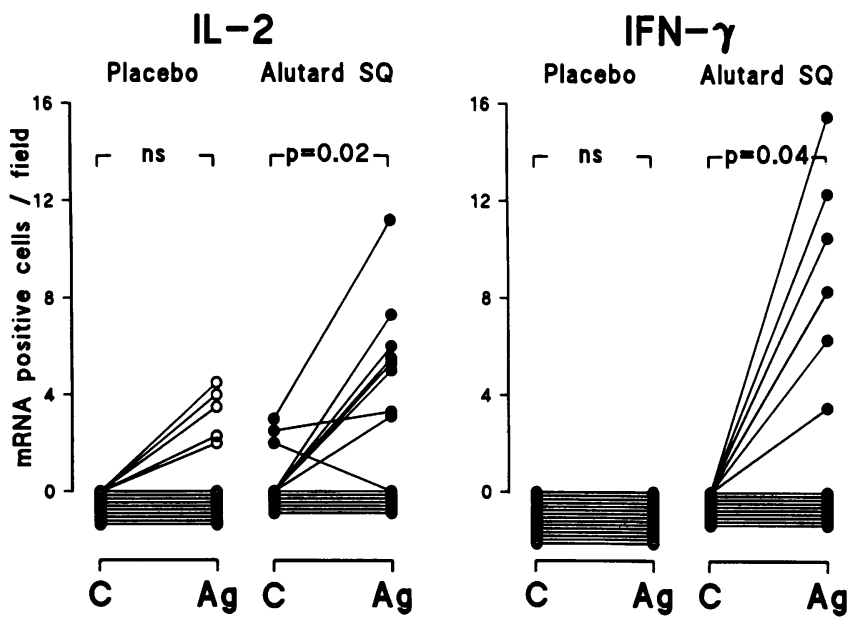

Figure 4. Expression of cytokine mRNA expression for IL-2 and IFN-gamma in the dermis in placebo (open circles) and Alutard SQ (closed circles) groups after 9 mo treatment. Results are expressed as mRNA+ cells per field $(\times 100) 24 \mathrm{~h}$ after intradermal $30 \mathrm{BU}$ grass pollen extract $(\mathrm{Ag})$ compared with counts after the control allergen diluent solution $(C)$. NS, not significant.

tients and a correlation between IL- 2 mRNA expression and CD25+ cell numbers. There was also increased expression of IFN-gamma in 6 of the 16 actively treated subjects. These observations provide a possible explanation for the mechanism of successful immunotherapy.

It is now well established that immunotherapy is associated with inhibition of allergen-induced late-phase responses in the skin $(17,18,19)$ and the lung $(11,12,20)$. In agreement with previous studies (19), we found highly consistent and marked reductions after immunotherapy in the size of the late-phase skin response to intradermal allergen. The size of the immediate skin weal was also significantly inhibited. As we have previously observed, there was no significant relationship between the size of the immediate and late-phase responses in individual subjects (21). For ethical reasons it was not possible to perform a time-course study with serial skin biopsies. The 24-h time point was chosen because our previous studies of the cutaneous late response $(13,15)$ identified maximal changes in $\mathrm{T}$ lymphocytes and eosinophils at this time. Thus, our findings represent a "snapshot" in what is clearly a dynamic process. This may partially explain the variability between subjects that we observed in cell counts and cytokine mRNA expression in each group.

The techniques used here do not permit the precise identification of the cells that express an increase in CD25 and HLA$\mathrm{DR}$ in the late-phase response after immunotherapy; to do this would require the use of double-immunostaining methods. However, in parallel work, we have recently confirmed in several forms of allergic tissue inflammation, including biopsies of late-phase cutaneous responses, that the majority of cells expressing CD25 at sites of allergic inflammation are indeed T cells $(65-85 \%)(22)$. It remains possible that some of the increased CD25 expression observed after immunotherapy may be on cells other than T lymphocytes. Similarly, it is not possible from our present findings to identify with certainty the precise cell type responsible for the positive hybridization signals for cytokine mRNAs. Although these cytokines were origi- nally described as $\mathrm{T}$ cell products, recent studies indicate that mast cells may produce IL-3, IL-4, and IL-5 $(23,24)$, while eosinophils are able to synthesize and secrete $\operatorname{GM}-\operatorname{CSF}(25,26)$ and IL-5 (27). The further identification of cells producing cytokines during late-phase responses and their modulation by immunotherapy would require simultaneous staining for cell surface phenotypic markers and for cytokines. Alternatively, immunohistology could theoretically be combined with in situ hybridization in the same sections, although the differing technical requirements of these two methods would make this difficult.

Immunotherapy was associated with lower median cell counts for allergen-induced mRNA expression for the cytokines IL-3, IL-4, IL-5, and GM-CSF, but none of these reductions was statistically significant. The significant increase in cytokine mRNA for IL-2 is consistent with the observed increase in IL-2R expression and is further supported by an observed positive correlation between IL- 2 mRNA+ cells and CD25+ cells. Increased IFN-gamma expression may possibly explain the increased HLA-DR expression observed at allergen-challenged sites in the Alutard SQ-treated patients. These findings are also compatible with recent in vitro studies of human allergen-specific T cell clones, in which induction of "tolerance" by high concentrations of allergen has been shown to induce increased expression of CD25 and HLA-DR (28) and an increase in IFN-gamma production (29). Induction of T cell tolerance by immunotherapy could perhaps account for the prolonged clinical improvement that has been observed after successful courses of immunotherapy (30).

Previous studies investigating the mechanisms of immunotherapy have examined a variety of serologic parameters but have not been able to determine a consistent pattern. For example, after an initial increase in allergen-specific serum IgE concentrations, immunotherapy is accompanied by blunting of the usual seasonal increase in specific IgE. Specific IgE then progressively declines over a period of months (4). Any clinical improvement invariably precedes the fall in specific IgE. The "blocking antibody" theory is based on the consistent finding that immunotherapy is associated with large increases in serum allergen-specific IgG concentrations, particularly IgG4 (5). More recently, alterations in anti-isotypic antibodies (antiIgE) after immunotherapy have been examined (6). Some investigators have reported an association between allergen-specific IgG and the clinical response (31), but in most studies changes in serum IgG, IgE, and anti-IgE bear no relationship to the clinical response (7).

Other proposed mechanisms for immunotherapy include reduction in serum concentrations of neutrophil chemotactic activity (32), reduced local numbers of eosinophils (33) and eosinophil cationic protein (34), and a reduction in the numbers of mast cells in the nasal mucosa (35). Immunotherapy has also been shown to suppress allergen-induced $T$ cell proliferative responses (36) and to induce an increase in circulating numbers of allergen-specific CD8+ lymphocytes (37). It is therefore of interest that the present study identified an increase in the number of CD8+ cells at diluent sites in patients in the active treatment group.

In the present study we chose not to address the peripheral blood $T$ cells but rather to concentrate on changes in the cells recruited to tissue inflammatory sites. It is probable that some of the changes observed after immunotherapy may have been 
due to systemic effects of treatment on $T$ cells as well as on mast cells and other nonlymphocytic effector cells. However, our previous work has shown selective recruitment of CD45RO+ $T$ cells to late-phase skin reaction sites $(38)$ and also found no relationship between CD4/CD8 ratios in blood and at latephase reaction sites in the skin (13) or nose (39). The primary reason for studying changes in tissue is that these reflect more closely what happens when individuals with clinical disease are exposed to allergen, while blood changes will give at best an indirect answer and may yield misleading conclusions (40).

With certain reservations, our study provides a novel insight into the possible mechanisms of immunotherapy. We did not identify significant correlations between seasonal symptoms and the size of the late cutaneous response or associated cellular changes within the Alutard-treated group. However, when the Alutard- and placebo-treated groups were compared, immunotherapy was accompanied by attenuation of the latephase response and suppression of recruitment of $\mathrm{T}$ lymphocytes and to a lesser extent eosinophils. In approximately half of the actively treated patients immunotherapy also induced a shift in the pattern of allergen-induced cytokine mRNA expression toward the induction of TH1-type cytokines. Expression of these TH1-type cytokines is compatible with our observed increase in expression of CD25 and HLA-DR. This is further supported by the positive correlation between cells positive for IL-2 mRNA and those positive for CD25.

If confirmed, our study points the way toward potential future molecular targets for immunotherapy. These include broad-based assaults on the CD4+ $\mathrm{T}$ helper subset using humanized monoclonal anti-CD4 antibodies (41), or strategies directed against $T$ cells expressing $T_{\mathrm{H}}$ 2-type cytokines (42), or against $T$ cells bearing particular cytokine receptors (43). Direct intervention with IFN-gamma is another possible approach; intramuscular IFN-gamma has been tried in seasonal ragweed hay fever in one study, but without any clinical improvement (44). The dose of IFN-gamma that could be administered was limited by systemic side effects and a trial of topical IFN-gamma might be more successful. Further options may become apparent with improvements in our understanding of the role of $\mathrm{T}$ cells in allergic disease.

\section{Acknowledgments}

We are grateful to ALK, Horsholm, Denmark, for the supply of allergen extracts for diagnosis and immunotherapy and for financial support, and to Wellcome Foundation Ltd. for supplying acrivastine (8mg capsules).

This work was supported by the National Asthma Campaign (UK) and the Medical Research Council (UK).

\section{References}

1. Norman, P. S. 1981. Immunotherapy. Prog. Allergy. 32:318-355

2. Malling, H. J. 1988. Specific immunotherapy. Position paper of the European Academy of Allergology and Clinical Immunology. Allergy Suppl. (CPH). 43(6):1-33.

3. Current status of allergen immunotherapy. Shortened version of a World Health Organisation/International Union of Immunological Societies Working Group Report. 1989. Lancet. i:259-261.

4. Lichtenstein, L. M., K. Ishizaka, P. S. Norman, A. K. Sobotka, and B. M. Hill. 1973. IgE antibody measurements in ragweed hayfever. Relationship to clinical severity and the results of immunotherapy. J. Clin. Invest. 52:472-482.

5. Djurup, R. 1985. The subclass nature and clinical significance of the IgG antibody response in patients undergoing allergen specific immunotherapy. $A l$ lergy (CPH). 40:469-486.

6. Kemeny, D. M., H. Tomioka, A. Tsutsumi, T. Koike, M. H. Lessof, and T. H. Lee. 1990. The relationship between anti-IgE auto-antibodies and the IgE response to wasp venom during immunotherapy. Clin. Exp. Allergy. 20:67-69.

7. Brunet, C., P. M. Bédard, A. Lavoie, M. Jobin, and J. Hébert. 1992. Allergic rhinitis to ragweed pollen. 1. Reassessment of the effects of immunotherapy on cellular and humoral responses. J. Allergy Clin. Immunol. 89:76-86.

8. Varney, V., M. Gaga, A. J. Frew, V. A. Aber, A. B. Kay, and S. R. Durham. 1991. Usefulness of immunotherapy in patients with severe summer hayfever uncontrolled by antiallergic drugs. Br. Med. J. 302:265-269.

9. Bousquet, J., P. Calvayrac, B. Guerin, A. Hejjaoui, H. Dhivert, B. Hewitt, and F.-B. Michel. 1985. Immunotherapy with a standardized D. pteronyssinus extract. I. In vivo and in vitro parameters after a short course of treatment. $J$. Allergy Clin. Immunol. 76:734-744.

10. Formgren, H., A. Lanner, N. Lindholm, O. Lowhagen, and S. Dreborg. 1984. Effects of immunotherapy on specific and non-specific sensitivity of the airways. J. Allergy Clin. Immunol. 73:140. (Abstr.)

11. Van Bever, H. P., and W. J. Stevens. 1989. Suppression of the late asthmatic reaction by hyposensitization in asthmatic children allergic to house dust mite (Dermatophagoides pteronyssinus). Clin. Exp. Allergy. 19:399-404.

12. Warner, J. O., J. F. Price, J. F. Soothill, and E. N. Hey. 1978. Controlled trial of hyposensitization to Dermatophagoides pteronyssinus in children with asthma. Lancet. ii:912-915.

13. Frew, A. J., and A. B. Kay. 1988. The relationship between infiltrating CD4+ lymphocytes, activated eosinophils, and the magnitude of the allergen-induced late-phase cutaneous reaction. J. Immunol. 141:4158-4164.

14. Kay, A. B., Sun Ying, V. Varney, M. Gaga, S. R. Durham, R. Moqbel, A. J. Wardlaw, and Q. Hamid. 1991. Messenger RNA expression of the cytokine gene cluster, IL-3, IL-4, IL-5 and GM-CSF in allergen-induced late-phase cutaneous reactions in atopic subjects. J. Exp. Med. 173:775-778.

15. Gaga, M., A. J. Frew, V. A. Varney, and A. B. Kay. 1991. Eosinophil activation and T-lymphocyte infiltration in allergen-induced late phase skin reactions and delayed-type hypersensitivity. J. Immunol. 147:816-822.

16. Varney, V. A., M. Gaga, A. J. Frew, and A. B. Kay. 1992. The effect of a single dose of prednisolone or cetirizine on inflammatory cells infiltrating allergen-induced late-phase reactions in atopic subjects. Clin. Exp. Allergy. 22:43-50.

17. Bos, J. D., and M. L. Kapsenberg. 1986. The skin immune system. Immunol. Today. 7:235-240.

18. Rocklin, R. E. 1989. Immune mechanisms in allergen specific immunotherapy. Clin. Immunol. Immunopathol. 53:S119-S131.

19. Fling, J. A., M. E. Ruff, W. A. Parker, B. A. Whisman, M. E. Martin, R. B Moss, and M. J. Reid. 1989. Suppression of the late cutaneous response by immunotherapy. J. Allergy Clin. Immunol. 83:101-109.

20. Metzger, W. J., B. A. Donnelly, and H. B. Richerson. 1983. Modification of late asthmatic responses (LAR) during immunotherapy for Alternaria-induced asthma. J. Allergy Clin. Immunol. 71:119. (Abstr.)

21. Frew, A. J., and A. B. Kay. 1988. The pattern of human late phase skin reactions to extracts of aeroallergens. J. Allergy Clin. Immunol. 81:1117-1121.

22. Hamid, Q., J. Barkans, D. S. Robinson, S. R. Durham, and A. B. Kay. 1992. Co-expression of CD25 and CD3 in atopic allergy and asthma. Immunology. 75:659-663.

23. Plaut, M., J. H. Pierce, C. J. Watson, J. Hanley Hyde, R. P. Nordan, and W. E. Paul. 1989. Mast cell lines produce lymphokines in response to cross-linkage of Fc epsilon RI or to calcium ionophores. Nature (Lond.). 339:64-67.

24. Wodnar-Filipowicz, A. C. H. Heusser, and C. Moroni. 1989. Production of the haemopoietic growth factors GM-CSF and interleukin-3 by mast cells in response to IgE receptor-mediated activation. Nature (Lond.). 339:150-152.

25. Moqbel, R., Q. Hamid, Sun Ying, J. Barkans, A. Hartnell, A. Tsicopoulos, A. J. Wardlaw, and A. B. Kay. 1991. Expression of mRNA and immunoreactivity for the granulocyte/macrophage colony-stimulating factor in activated human eosinophils. J. Exp. Med. 174:749-752.

26. Kita, H., T. Ohnishi, Y. Okubo, D. Weiler, J. S. Abrams, and G. J. Gleich. 1991. Granulocyte/macrophage colony-stimulating factor and interleukin 3 release from human peripheral blood eosinophils and neutrophils. J. Exp. Med. 174:745-748.

27. Desreumaux, P., A. Janin, J. F. Colombel, L. Prin, J. Plumas, D. Emilie, G. Torpier, A. Capron, and M. Capron. 1992. Interleukin 5 messenger RNA expression by eosinophils in the intestinal mucosa of patients with coeliac disease. J. Exp. Med. 175:293-296.

28. O'Hehir, R. E., B. A. Aguilar, T. J. Schmidt, S. O. Gollnick, and J. R. Lamb. 1991. Functional inactivation of Dermatophagoides spp. (house dust mite) reactive human T-cell clones. Clin. Exp. Allergy. 21:209-215.

29. O'Hehir, R. E., H. Yssel, V. Sunita, J. E. de Vries, H. Spits, and J. R. Lamb. 1991. Clonal analysis of differential lymphokine production in peptide and superantigen induced T cell anergy. Int. Immunol. 3:819-826.

30. Mosbech, H., and O. Osterballe. 1988. Does the effect of immunotherapy last after termination of treatment? Follow-up study in patients with grass pollen rhinitis. Allergy. 43:523-529. 
31. Lichtenstein, L. M., P. S. Norman, and W. L. Winkenwerder. 1971. A single year of immunotherapy for ragweed hayfever: immunologic and clinical studies. Ann. Intern. Med. 75:663-671.

32. McHugh, S. M., and P. W. Ewan. 1989. Reduction of increased serum neutrophil chemotactic activity following effective hyposensitization in house dust mite allergy. Clin. Exp. Allergy. 19:327-334.

33. Furin, M. J., P. S. Norman, P. S. Creticos, D. Proud, A. Kagey-Sobotka, L. M. Lichtenstein, and R. M. Naclerio. 1991. Immunotherapy decreases antigen-induced eosinophil migration into the nasal cavity. J. Allergy Clin. Immunol. 88:27-32.

34. Rak, S., O. Lowhagen, and P. Venge. 1988. The effect of immunotherapy on bronchial hyperresponsiveness and eosinophil cationic protein in pollen allergic patients. J. Allergy Clin. Immunol. 82:470-480.

35. Otsuka, H., A. Mezawa, M. Ohnishi, K. Okubo, H. Seki, and M. Okuda. 1991. Changes in nasal metachromatic cells during allergen immunotherapy. Clin. Exp. Allergy. 21:115-119.

36. Rocklin, R. E., A. L. Sheffer, D. R. Greineder, and K. L. Melmon. 1980. Generation of antigen-specific suppressor cells during allergy desensitization. $N$. Engl. J. Med. 302:1213-1219.

37. Nagaya, H. 1985. Induction of antigen-specific suppressor cells in patients with hayfever receiving immunotherapy. J. Allergy Clin. Immunol. 75:388-394.

38. Frew, A. J., and A. B. Kay. 1991. UCHL1+ (CD45RO+) "memory" T-cells predominate in the $\mathrm{CD} 4+$ cellular infiltrate associated with allergen-in- duced late-phase skin reactions in atopic subjects. Clin. Exp. Immunol. 84:270274.

39. Varney, V. A., M. R. Jacobson, R. M. Sudderick, D. S. Robinson, A.-M. A. Irani, L. B. Schwartz, I. S. Mackay, A. B. Kay, and S. R. Durham. 1992. Immunohistology of the nasal mucosa following allergen-induced rhinitis. Identification of activated T lymphocytes, eosinophils and neutrophils. Am. Rev. Respir. Dis. 146:170-176.

40. Frew, A. J., and R. E. O'Hehir. 1992. What can we learn from studies of lymphocytes present in allergic reaction sites? J. Allergy Clin. Immunol. 89:783788.

41. Herzog, C., C. Walker, W. Müller, P. Rieber, P. Reiter, C. Riethmüller, P. Wassmer, H. Stockinger, O. Madic, and W. J. Pichler. 1989. Anti-CD4 antibody treatment of patients with rheumatoid arthritis. I. Effect on clinical course and circulating T cells. J. Autoimmun. 2:627-642.

42. Chand, N., J. E. Harrison, S. Rooney, J. Pillar, R. Jackubicki, K. Nolan, W. Diamantis, and R. D. Sofia. 1992. Anti-IL-5 monoclonal antibody inhibits allergic late phase bronchial eosinophilia in guinea pigs: a therapeutic approach. Eur. J. Pharmacol. 211:121-123.

43. Fanslow, W. C., K. N. Clifford, A. S. Rubin, R. F. Voice, M. P. Beckman, and M. B. Widmer. 1991. Regulation of alloreactivity in vivo by IL-4 and the soluble IL-4 receptor. J. Immunol. 147:535-540.

44. Li, J. T., J. Yunginger, C. E. Reed, D. R. Nelson, H. Jaffe, J. Hallagan, J. Blomgren, and G. J. Gleich. 1989. Recombinant interferon-gamma in the treatment of allergic rhinitis. J. Allergy Clin. Immunol. 83:307. (Abstr.) 